\title{
Metformin: A Drug of Choice for Gestational Diabetes Mellitus in Near Future- Hope or Despair?
}

\section{A S M Towhidul Alam \\ Shaheda Ahmed ${ }^{2 *}$}

'Department of Biochemistry Cox's Bazar Medical College Cox's Bazar, Bangladesh.

${ }^{2}$ Department of Biochemistry International Islamic Medical College Chittagong, Bangladesh.

${ }^{*}$ Correspondence to:

\section{Dr. Shaheda Ahmed}

Assistant Professor

Department of Biochemistry

International Islamic Medical College

Chittagong, Bangladesh.

Mobile: +8801715704218

E-mail: perveen71@gmail.com

www.banglajol.info/index.php/CMOSHMCJ

\begin{abstract}
Pregnancy is a potentially glucose intolerant condition. Insulin sensitivity decreases as the pregnancy advances. At the later stage of pregnancy, some women develop Gestational Diabetes Mellitus (GDM) particularly obese with pre-existing insulin resistance. Insulin is recognized as the "gold standard" for the treatment of GDM. However, difficulty in administration with multiple daily injections, potential for hypoglycemia, and increase in appetite and weight, make this therapeutic option troublesome for many pregnant patients. Oral hypoglycaemic drugs have been viewed with suspicion for many years in the management of women with diabetes during pregnancy or breastfeeding. However, recent data from well designed trials and meta-analysis may contribute a visible change in practice in terms of oral agents, especially metformin in gestational diabetes. Some cohort data are available and randomized trials are currently in progress to compare metformin with insulin. Evidence is emerging that metformin may improve insulin sensitivity during pregnancy. This may be beneficial in GDM. Use of metformin in pregnancy has opened a new horizon for GDM management. The aim of this article is to review the safety, efficacy and future of metformin in diabetic pregnancy, thus contributing meaningfully in safe motherhood.
\end{abstract}

Key words: Gestational Diabetes Mellitus (GDM); Insulin; Oral hypoglycaemic drugs; Metformin.

\section{BACKGROUND}

The incidence of GDM depends on the diagnostic criteria used and varies widely between racial groups ${ }^{1}$. Overall incidence is reported as $3-6 \%$, but has steadily increased over time, ranging from $2 \%$ in South America to $5 \%{ }^{3}$ in the United States to $15 \%$ in the Indian subcontinent ${ }^{2-4}$. GDM has long been recognized as a risk factor for a number of adverse outcomes during pregnancy, including excessive fetal growth, an increased incidence of birth trauma and cesarean delivery, and neonatal metabolic abnormalities such as polycythemia, hyperbilirubinemia and hypoglycemia ${ }^{5}$. Maternal complications include risk of hypertensive disease, preeclampsia, cesarean delivery ${ }^{6-8}$ and a greater risk of developing diabetes mellitus later on $6,7,8$.

Gestational Diabetes Mellitus (GDM) is classically defined as "Carbohydrate intolerance resulting in hyperglycemia of variable severity with onset or first recognition during pregnancy"9. It does not rule out a prior unidentified glucose intolerance, and in fact several studies have found $10 \%$ to $15 \%$ of cases of undiagnosed type 2 diabetes mellitus among GDM patients ${ }^{10}$. Insulin resistance increases in normal pregnancy due to progressively rising levels of feto-placental hormones such as progesterone, cortisol, growth hormone, prolactin, and human placental lactogen ${ }^{11}$. The pancreas normally compensates by increasing insulin secretion, but when it fails to do so, or when insulin secretion declines due to a beta- 
cell function impairment, then GDM develops ${ }^{11,12,13}$. Maternal hyperglycemia, which is classical for GDM, causes increase transfer of glucose to the fetus, causing fetal hyperinsulinemia an overgrowth of insulin-sensitive (Mainly adipose) tissues, with consequent excessive, unbalanced fetal growth, causing more trauma at birth, shoulder dystonia and perinatal deaths ${ }^{7,8,14}$

Presently, there is consensus that the recommendations of the Fourth and the Fifth International Workshop Conference (FIWC) on GDM to maintain maternal capillary whole blood glucose concentrations below $96 \mathrm{mg} / \mathrm{dl} \quad(<5.3 \mathrm{mmol} / \mathrm{l})$ in the fasting state and either below $140 \mathrm{mg} / \mathrm{dl}(<7.8 \mathrm{mmol} / \mathrm{l})$ at 1 hour or below $120 \mathrm{mg} / \mathrm{dl}(<6.7 \mathrm{mmol} / \mathrm{l})$ at 2 hour after starting the meal should be the treatment targets ${ }^{15,16}$. The goal of glucose management in GDM is to keep glucose values as near normal as possible. The reference plasma glucose levels suggested by the American Diabetes Association (ADA) are below $105 \mathrm{mg} / \mathrm{dl}(<5.8 \mathrm{mmol} / \mathrm{l})$ before meals and either below $155 \mathrm{mg} / \mathrm{dl}(<8.6 \mathrm{mmol} / \mathrm{l}) 1$ hour afterwards, or below 130 $\mathrm{mg} / \mathrm{dl}(<7.2 \mathrm{mmol} / \mathrm{l}) 2$ hour afterwards ${ }^{17}$.

Measuring glucose levels after meals is more important than pre-prandial levels in GDM patients because it correlates better with certain adverse neonatal events, e.g., malformations, macrosomia, hypoglycemia and shoulder dystocia ${ }^{18,19}$.

\section{History of Metformin}

Metformin is a dimethylbiguanide, first described in scientific literature in $1957^{20}$. This compound originates from the French lilac ( Galega officinalis) a plant known for several centuries to ameliorate the symptoms of $\mathrm{DM}^{21}$. Metformin has a multiple mechanism of actions, comprising decreasing hepatic glucose output, increasing insulin sensitivity and insulin-mediated glucose uptake in the peripheral tissues (Muscle and liver) lowering serum-free fatty acid concentration through antilipolytic effect and increasing intestinal glucose use ${ }^{22-26}$. The activation of the enzyme AMP mediated protein kinase is an important mechanism by which Metformin lowers the blood glucose levels ${ }^{27}$. These effects of Metformin make it an attractive choice in diabetic pregnancy because it decreases peripheral insulin resistance, does not cause hypoglycaemia nor increase insulin secretion ${ }^{28}$.

Metformin is a category B drug, indicating that there is no evidence of fetal or animal teratogenicity ${ }^{29}$. Metformin smoothly crosses the placenta and henceforth there is concern regarding possible adverse effects on the fetus ${ }^{30-31}$. Despite valid concerns, there have been clinical reports of Metformin use in diabetic pregnancy since $1966 .^{32-35}$ In those earlier studies, mainly from South Africa, the authors conclude that Metformin 'appears' to be safe for use in $\mathrm{GDM}^{28}$.

\section{Pharmacology and Actions of Metformin}

The biguanide, Metformin, is the most widely prescribed insulin sensitizer in the therapeutic management of Type 2 Diabetes (T2D) ${ }^{36}$. Although the liver is the primary target organ, metformin acts on a variety of tissues, namely skeletal muscles, adipose tissue, endothelium and the ovary ${ }^{36}$.

\section{Function in Liver}

The Metformin-induced inhibition of hepatic gluconeogenesis has been postulated to several mechanisms. Potential mechanisms are the direct inhibition of gluconeogenic enzymes (e.g. Phosphoenolpyruvate carboxykinase, fructose1,6-bisphosphatase and glucose-6-phosphatase) the reduced hepatic uptake of substrate for gluconeogenesis and the increased phosphorylation of Insulin receptor and Insulin Receptor Substrates (IRS)-1 and -2 ${ }^{37-42}$. Metformin stimulates glucose entry into the liver and glycolysis through the activation of glycolytic enzymes, such as hexokinase (Glucokinase) and pyruvate kinase ${ }^{37,43}$.

\section{Function in Skeletal Muscle}

Skeletal muscle accounts for more than $80 \%$ of insulinstimulated glucose uptake ${ }^{44}$. In cultures of insulin resistant skeletal muscle cells, Metformin was able to restore insulin signaling defects, including the reductions in insulinstimulated insulin receptor and IRS-1 phosphorylation and in Phosphatidylinositol-3 kinase (PI3K) activity ${ }^{44}$.

\section{Function in Adipose Tissue}

Adipose tissue has been recognized as an endocrine organ with a dual role in the regulation of insulin sensitivity and energy homeostasis ${ }^{45}$. Metformin was shown to stimulate catabolism in preadipocytes, as reflected by increases in glucose transport and utilization, mitochondrial and peroxisomal FA $\beta$ oxidation, basal lipolysis, and aerobic and anaerobic respiration (i.e. Lactate production). More specifically, chronic Metformin treatment of type 2 diabetes significantly enhanced glucose uptake in visceral fat depot ${ }^{46,47}$.

\section{Function in the Ovary}

Metformin appears to affect ovarian function in a dual mode, through the alleviation of insulin excess acting upon the ovary and through direct ovarian effects ${ }^{48}$.

\section{Function on Endothelium}

Metformin was reported to improve endothelium dependent vasodilation in insulin resistant patients, thus potentially protecting against atherogenesis ${ }^{49}$.

\section{Studies of Metformin in Pregnancy}

There have been clinical reports of Metformin use in diabetic pregnancy since 1966 mainly from South Africa ${ }^{32-35}$. In those earlier studies, mainly from South Africa, the authors conclude that Metformin 'appears' to be safe for use in $\mathrm{GDM}^{28}$. Data obtained from a small meta-analysis that included 172 women, from 8 studies, who were exposed to Metformin in the first trimester, either due to polycystic ovary syndrome or due to diabetes, did not find an increased risk of major malformations when compared to controls ${ }^{50}$. This meta-analysis, though included a small number of women, suggested that Metformin is not a teratogenic drug and that its use might be extended to pregnant women. However, an earlier study showed that Metformin use in diabetic pregnant women significantly increase the prevalence of pre-eclampsia and the rate of perinatal mortality $(32 \% \text { and } 11.6 \% \text { respectively })^{51}$. Beside the 
probable safety of Metformin use in the first trimester, investigators studied its effects and safety profile when used for the control of GDM in the second and third trimester of pregnancy ${ }^{52}$.

\section{Metformin in Polycystic Overy Syndrome (PCOS)}

The first study reporting the beneficial effects of Metformin on reproductive as well as metabolic aberrations of Poly Cystic Ovary Syndrome (PCOS) was published in 1994 in the United States $^{53}$. This study found that a 2-month Metformin treatment in 26 obese PCOS led to the attenuation of hyperinsulinemia, reduction of androgen levels, and regularization of menses. Two years later, administration of Metformin to women with PCOS was shown to decrease ovarian 17,20-lyase activity and ovarian androgen secretion, while lowering insulin levels ${ }^{48}$. Since then, clinical studies have addressed the impact of Metformin treatment on hyperandrogenemia in women with $\mathrm{PCOS}^{54}$. Metformin either alone or in combination with Clomiphene Citrate (CC) is a pharmaceutical option for ovulation induction in women with $\mathrm{PCOS}^{55}$.

\section{Metformin vs Insulin}

The first studies on Metformin was done by Coetzee and Colleagues during the $1970 \mathrm{~s}^{33}$. Initial data on the efficacy of metformin comes from Coetzee's study in the late 1970s of 160 treated patients with established insulin independent diabetes ${ }^{33}$. In this study, $14 \%$ of patients were able to maintain good glycaemic control, as defined by a fasting glucose of 5.5 $\mathrm{mmol} / \mathrm{l}$ and a post-prandial value below $6.7 \mathrm{mmol} / \mathrm{l}$ on a combination of diet and Metformin, compared with about $26 \%$ of women who needed insulin. In a follow up study, Coetzee was able to achieve glycemic control in women on Metformin within 24 hours compared with 2-3 weeks for insulin ${ }^{34}$.

An Australian study (Metformin in Gestational Diabetes-MiG study) conducted by Rowan and colleagues included 751 women (371 received Metformin, and 378 received insulin) who were randomized between 20 and 33 weeks of pregnancy ${ }^{52}$. It was the largest study so far reported of Metformin use in women with $\mathrm{GDM}^{52}$. The Metformin failure rate was $7.4 \%$, in which a second diabetic agent was needed to maintain controlled glucose levels. Although there was no difference in mean fasting blood glucose levels between groups, those on Metformin, had lower 2-hour postprandial glucose levels. There was no difference in the rate of preeclampsia. Women in the Metformin group had less weight gain compared to women in the insulin group ${ }^{52}$. A comparable, but much smaller, randomized trial of 63 patients found similar results $^{56}$

Historically, some of the earliest reports of the use of Metformin during pregnancy have come from South Africa, where it has been used since the late 1970s for women with both type 2 diabetes and GDM ${ }^{33}$. While perinatal mortality for these women was still higher than that seen in the general obstetric population, it was however lower than in women who had gone untreated and similar to those who were changed to insulin ${ }^{33}$. Infants of women randomized to Metformin experienced a lower rate of hypoglycemia compared with insulin (insulin $8.1 \%$ vs. metformin $3.3 \%, \mathrm{P}=0.008$ ). There was no difference in any other perinatal outcome ${ }^{52}$.
Metformin has been found to have a maternal-to-fetal transfer rate of $10-16 \% 57$. Neonatal hypoglycemia is always a concern postnatally. However, in several reports on the infants in the immediate neonatal period, there was no increase in the rate of neonatal hypoglycemia after delivery compared with women who received insulin. In those who did develop neonatal hypoglycemia, it was determined that this outcome was related to maternal hyperglycemia at the time of delivery ${ }^{33}$. There was no case of neonatal lactic acidosis. Preliminary data on the possibility that infants of diabetic mothers exposed to Metformin in utero may experience a reduction in insulin resistance is contained in the article by Rowan et al in the issue of Diabetes Care ${ }^{58}$. In this first follow-up of the MiG study, infants of women with GDM who had been randomized to receive either Metformin or insulin during pregnancy have been examined at 2 years of age. Rowan et al found that the offspring exposed to Metformin in utero had increased subscapular and biceps skinfolds when compared to the unexposed infants, while total body fat was similar. They hypothesized that this represents a possible benefit as this may signal a healthier fat distribution.

\section{Metformin vs OHA( Glyburide) vs Insulin}

The eight Randomized Controlled Trials (RCTs) were published between 2000 and 2010 and were conducted in different countries and populations. Four trials were conducted in the United states two in Brazil one in India and one in Australia and New Zealand ${ }^{56,59-61}$.

Two trials compared glyburide with Metformin, the maximum Glyburide dose was $20 \mathrm{mg}$ daily and that of Metformin was $2500 \mathrm{mg}$ daily ${ }^{56,60,61}$.

Moore and colleagues randomly assigned 149 women to Metformin $(\mathrm{N}=75)$ or Glyburide $(\mathrm{N}=74)^{62} . \quad 12 \%$ participants on Glyburide and $26 \%$ on Metformin required additional insulin therapy.

Silva and colleagues randomised 72 to Metformin $(\mathrm{N}=32)$ or Glyburide $(\mathrm{N}=40)^{63}$. $10 \%$ of those receiving Glyburide and $8 \%$ of those on Metformin subsequently required insulin therapy.

Moore and colleagues reported significantly fewer caesarean deliveries in the Glyburide group compared with the Metformin group ( $3 \%$ vs. $15 \% ; p=0.02)^{62}$. By contrast, Silva and coinvestigators reported no difference in the caesarean delivery rate between treatment groups $(70 \% \text { vs } 69 \%, p=0.9)^{63}$. Moore also reported no difference in FBG levels between the two groups $(p=0.23)$. Moore reported no difference in the rate of pre-eclampsia $(p>0.5)$. Two RCTs evaluated neonatal hypoglycemia (Defined as capillary glucose less than 40 $\mathrm{mg} / \mathrm{dl}$ ), macrosomia and infant birth weight. Both reported no significant differences in neonatal hypoglycemia. Moore reported no difference in the proportion of infants weighting more than $4000 \mathrm{~g}$ in the Glyburide group compared with the Metformin group ( $1.3 \%$ vs $5.4 \% ; \mathrm{p}=0.2)$. Silva reported no differences between groups in infants weighing more than 
$4000 \mathrm{~g}(\mathrm{p}=0.24)$ or LGA infants $(\mathrm{p}=0.14)$. Infants born to mothers receiving Glyburide were, on average, $200 \mathrm{~g}$ heavier than infants born to mothers receiving Metformin ( $3329 \pm 334$ vs. $3103 \pm 600 \mathrm{~g}, \mathrm{p}=0.02$ ) (Moore, 2010). Silva and colleagues reported a slightly higher mean birth weight in the Glyburide group (103 g), but this difference is not statistically or clinically significant.

\section{Key findings between Metformin and Glyburide}

- No difference in FBG level.

- Almost one third of participants receiving Metformin in the study by Moore required insulin.

- Moor reported that infants were, on average, $200 \mathrm{~g}$ heavier in the Glyburide group compared with the metformin group, which is statistically significant and clinically relevant.

Five of the six studies compared an oral diabetes medication with insulin and reported the percentage of participants initially placed on an oral medication who ultimately required insulin ${ }^{56}$.

Two of the five studies reported no participants requiring supplementation with insulin. Three of the five studies reported a wide range of participants who required insulin, ranging from $4 \%$ to $6 \%$ to $47 \%{ }^{56,61,62-65}$. The average gestational age at screening and diagnosis of GDM varied across studies from 22 to 25 gestational weeks. Six of the RCTs were under randomization scheme $\mathrm{s}^{5,61,64}$. None was blinded. Four trials reported participant withdrawals or the reasons for loss to follow-up ${ }^{59,61}$. Only two studies reported an intention-to treat analysis $^{64}$. Rowan and colleagues randomly assigned 751 women at 20-33 weeks of gestation to Metformin or insulin ${ }^{61}$. $92 \%$ of the participants on Metformin continued to receive Metformin alone. A smaller trial randomly assigned 63 women to Metformin or insulin ${ }^{56}$. Who started Metformin initially, continued to receive Metformin. There was no difference in the mean standard deviation FBG levels between women treated with Metformin and those treated with insulin (FBG 93.6 \pm 11 compared with $91.8 \pm 13 \mathrm{mg} / \mathrm{dl}, \mathrm{p}=0.24$ ) among participants in the larger study by Rowan. Moore also reported no difference in FBG $(92.6 \pm 10 \text { compared with } 97 \pm 9 \mathrm{mg} / \mathrm{dl} ; \mathrm{p}=0.4)^{56}$. Both trials reported no difference in caesarean delivery rates. Only Rowan trial evaluated maternal weight, pre-eclampsia and preterm birth ${ }^{61}$. There was no difference in the rate of preeclampsia. Maternal weight gain was substantially less in the Metformin group compared with the insulin group $(\mathrm{p}<0.001)$. Rowan reported higher rates of pre-term labour in the Metformin group compared with the insulin group $(\mathrm{p}=0.02)$. Both Rowan and Moore evaluated neonatal birth weight and neonatal hypoglycemia ${ }^{56,61}$. Rowan reported a higher proportion of infants with hypoglycemia (defined as any blood glucose less than $28.8 \mathrm{mg} / \mathrm{dl}$ ) with insulin compared to Metformin $(p=0.008)$, whereas Moore reported no substantial differences $(p=0.14)$. Trail by Rowan did not report any differences in birth weights between treatment groups (3372 \pm $572 \mathrm{~g}$ in the Metformin group vs $3413 \pm 569 \mathrm{~g}$ in the insulin group, $p=0.3$ ). Similar findings found by Moore ( $3451 \pm 727$ $\mathrm{g}$ vs. $3500 \pm 700 \mathrm{~g}, \mathrm{p}=0.8$ ). There were no differences in birth trauma, respiratory distress or the 5-min Apgar score ${ }^{56,65}$.

\section{Key Findings Between Metformin and Insulin}

- No difference in FBG between the Metformin and Insulin groups.

- The larger RCT reported a higher proportion of infants with an episode of hypoglycemia with Insulin compared to Metformin, the smaller trial reported no differences, but had limited statistical power to detect meaningful differences.

- No differences in the proportion of infants with a congenital anomaly between treatment groups were reported in the larger RCT by Rowan. Data on congenital anomalies were not collected in the smaller trial.

The larger study by Rowan contributes most of the evidence for the effectiveness and safety of Metformin.

There has been much debate about efficacy and safety of Oral Antidiabetic Drugs (OADs) for use in GDM patients. The National Institute for Health and Care excellence (NICE) clinical practice guidelines recommend use of Metformin and Glyburide instead of insulin if life style interventions fail to control glycemic levels ${ }^{66}$. After a long debate, the new clinical practice guidelines of the American College of Obstetricians and Gynecologists (ACOG) also recommend use of these two agents in GDM patients as alternatives to insulin therapy and consider the combination equally effective ${ }^{67}$.

In another study showed no significant difference in the use of Metformin or insulin $(\mathrm{p}=0.15)$ when compared the efficacy of Metformin vs human insulin in GDM patients. $84 \%$ of insulin group had good Glycemic control whereas in Metformin group, $72 \%$, achieved euglycemic state ${ }^{68}$. 30\% of Metformin group underwent spontaneous vaginal delivery whereas only $20 \%$ in the insulin group. During postnatal period, it was seen that 2 babies expired in the neonatal period in the insulin group only. No such mishap occurred in the Metfromin receiving group. Hypoglycemia developed in 4 babies of insulin group and 2 cases in Metformin group. There were no cases of RDS in either group. No cases of congenital anomaly in either group were detected. The neonatal outcome was similar in both groups $(\mathrm{P}=0.33) .80 \%$ of the patients felt that the repeated injections were the most difficult part of the treatment. $64 \%$ of the entire study group felt taking oral medications was the easiest part of the study.

\section{Key Points}

- Glycemic control is similar in both groups.

- Maternal weight gain and neonatal hypoglycemia is prominent in insulin group.

- No congenital anomaly in both groups.

- Pre-term labour rates are high in Metformin group.

- No noticeable difference in the relevant neonatal outcomes between two groups.

- Most patients liked Metformin due to its easier ( Oral) route of administration. 


\section{Metformin in Lactation}

Limited amount of Metformin are transferred into breat milk, but the risk of neonatal hypoglycemia is negligible ${ }^{69}$. The milk:serum or milk:plasma ratio varied between 0.18 and 1.00 , while the estimated mean infant dose as a percentage of the mother's weight-adjusted dose varied between $0.18 \%$ and $1.08 \%$. This dose is much less than the usual $10 \%$ level of the concern $^{70}$. There is no risk of neonatal hypoglycemia, in contrast to the use of drugs stimulating insulin release, such as the sulfonylureas. Maintenance of maternal euglycaemia during lactation remains an important principle to reduce the risk of subsequent obesity in the child in future ${ }^{71}$.

\section{Comparison of Other Hypoglycemic Drug with Insulin Glyburide or Glibenclamide vs Insulin}

Glyburide or glibenclamide is a second-generation sulphonylurea ${ }^{72}$. Study showed that glyburide significantly

increased the risk of macrosomia (RR, 3.07; 95\% CI, 1.14 $8.23, \mathrm{p}$-value $=0.03)$ and neonatal hypoglycemia $(\mathrm{RR}, 2.30$, $95 \%$ CI, 1.28-4.11, p-value $=0.005)$ compared to insulin ${ }^{73}$. Study showed no difference between insulin and glyburide with regard to risk for LGA birth, preterm births, neonatal mortality, congenital abnormality ${ }^{73}$. Maternal outcomes such as caesarean section, pre-eclampsia, maternal hypoglycemia and glycemic levels displayed no significant difference between glyburide and insulin ${ }^{73}$.

\section{Acarbose vs Insulin}

Acarbose, an alpha glucosidase inhibitor, preliminary studies have suggested efficacy in reducing postprandial hyperglycemia in GDM, but its use has been limited due to the frequency of abdominal cramping ${ }^{74}$.

\section{Use of Metformin in Pregnancy}

- Advantages: Though insulin is the first choice in GDM, however Metformin definitely can be used in situations where insulin administration is not feasible or not accepte by the patient or in combination with insulin incase of the demand of the situation. Metformin is not responsible for neonatal complications in terms of malformations, birth weight or neonatal hypoglycemia ${ }^{75}$. Metformin has been associated with fewer cases of GDM among women with polycystic ovary syndrome ${ }^{76}$. It is a safe and effective alternative in women with GDM and those with Type 2 diabetes who become pregnant ${ }^{77}$.
- Disadvantages: Metformin has been shown to cross the placenta, with fetal level becoming about half those of the mother ${ }^{78}$. The frequently observed gastrointestinal adverse effects include diarrhea, flatulence, nausea, and vomiting, with the incidence ranging from 2 to $63 \%$, but resolve within a few days to weeks after the initiation of therapy ${ }^{6,79}$. Lactic acidosis has been rarely reported with the use of Metformin, mostly in patients with contraindications to the drug or in cases of intoxication after drug overdosage ${ }^{80}$. It has been shown from clinical practice by physicians that fine tuning or accurate dose adjustment (For fasting or $2 \mathrm{hrs}$ postprandial) is not possible by Metformin alone. Moreover, cases where insulin is required in high dose such as more than 30 to 40 units/ day, Metformin cannot be used alone as a substitute of insulin.

\section{CONCLUSIONS}

We believe that in near future accumulation of more evidence will bring a change in clinical practice towards using Metformin in diabetic pregnancy as an efficacious alternative to insulin therapy especially in patients with mild form of disease, shifting the "mind setup" against the use of oral hypoglycemic drugs in gestational diabetes under normal circumstances ${ }^{73}$. This will be particularly beneficial for the developing countries, where rates of diabetes are greatly increasing and the expense of insulin treatment can be minimized. Metformin currently is approved by the US Food and Drug Administration (FDA) for use in the treatment of type 2 diabetes ${ }^{81}$. Its off-label use in the treatment of infertility caused by Poly Cystic Ovary Syndrome (PCOS) has been growing over the past decade ${ }^{50}$. Further long term outcome data will add more positive impacts for Metformin use in GDM.

\section{DISCLOSURE}

All the authors declared no competing interest. 


\section{REFERENCES}

1. Nicholson W \& Baptiste-Roberts K. Oral hypoglycaemic agents during pregnancy: The evidence for effectiveness and safety. Best Practice \& Research Clin Obstet and Gynecol. 2011; 25: 51-63.

2. Jovanovic L \& Pettitt DJ. Gestational diabetes mellitus. JAMA. 2001; 286(20): 2516-2518.

3. Ferrara A, Kahn H, Quesenberry CP et al. An increase in the incidence of gestational diabetes mellitus: Northern California. Obstet Gynecol. 2004; 103: 526-533.

4. Beischer NA, Oats J, Henry OA et al. Incidence and severity of gestational diabetes mellitus according to country of birth in women living in Australia. Diabetes care. 1991; 40(Supple.2): 35-38.

5. Brody SC, Harris R, Lohr K. Screening for gestational diabetes: a summary of the evidence for the U.S. Preventive Services Task Force. Obstet Gynecol. 2003; 101: 380-392.

6. Yogev Y, Xenakis E \& Langer O. The relation between preeclampsia and the severity of gestational diabetes. Am J Obstet Gynecol. 2004; 191: 1655-1660.

7. Casey BM, Lucas MJ, Mclntire DD, Leveno KJ. Pregnancy outcomes in women with gestational diabetes compared with the general obstetric population. Obstet Gynecol. 1997; 90: 869-873.

8. Kjos AL, Buchanan TA. Gestational diabetes mellitus. N Engl J Med. 1999; 341: 1749-1756.

9. Expert Committee on the Diagnosis and Classification of Diabetes Mellitus. Report of the Expert committee on the diagnosis and classification of diabetes mellitus. Diabetes care. 1997; 20: 1183-1197.

10. Langer O. Type 2 diabetes in pregnancy: exposing deceptive appearances. J Matern Fetal Neonatal Med. 2008; 21(3): 181-189.

11. Ryan EA, Enns L. Role of gestational hormones in the induction of insulin resistance. J Clin Endocrinol Metab. 1988; 67: $341-347$.

12. Kuhl C. Etiology and pathogenesis and gestational diabetes. Diabetes Care. 1998; 21: B19-B26.

13. Lapolla A, Dalfra MG, Mello G, et al. Early detection of insulin sensitivity and beta cell function with simple tests indicate future derangements in late pregnancy. J Clin Endocrinol Metab. 2008; 93(3): 876-880.

14. Pedersen J. The Pregnant Diabetic and her Newborn. Munksgaard: Copenhagen and Williams and Wilkins. Baltimore. 1977; 2:211.

15. Metzger BE, Coustan DR. The organizing committee: Summary and recommendations of the Fourth International Workshop-Conference on Gestational Diabetes mellitus. Diabetes Care. 1998; 21 Suppl 2: 161-167.

16. Metzer BE, Buchanan TA, Coustan DR, et al. Summary and Recommendations of the Fifth International Workshop-Conference on Gestational Diabetes Mellitus. Diabetes Care. 2007; 30(2): S251-S260.

17. American diabetes Association. Gestational Diabetes Mellitus (Position Statement). Diabetes Care. 2004; 27(Suppl 1): S88-S90.

18. Jovanovic-Peterson L, Peterson CM, Reed GF, Metzger BE, Mills JL, Knopp RH, et al. Maternal postprandial glucose levels and infant birth weight: Diabetes in Early Pregnancy Study: The national institute of Child Health and Human Development- Diabetes in Early Pregnancy Study. Am J Obstet Gynecol. 1991; 164:103-111.

19. De Veciana M, Major CA, Morgan MA, Asrat T, Toohey JS, Lien JM, et al. Post prandial versus preprandial blood glucose monitoring in women with gestational diabetes mellitus requiring insulin therapy. N Engl J Med. 1995; 333: 1237-1241.

20. Bell PM, Hadden DR. Metformin. Endocrinol metab Clin North Am. 1997; 26: 523-537.

21. Witters LA. The blooming of the French Iiliac. J Clin Invest. 2001; 108: 1105-1107.

22. Bailey CJ, Wilcock C, Day C. Effect of metformin on glucose metabolism in the splanchnic bed. Br J Pharmacol. 1992; 105: 1009-1013.

23. Bailey CJ, Turner RC. Metformin. N Engl J Med. 1996; 334: 774-579.

24. Rossetti L, DeFronzo RA, Ciherzi R et al. Effect of metformin treatment on insulin action $\mathrm{n}$ diabetic rats: in vivo and in vitro correlations. Metabolism. 1990; 39: 425-435.

25. Stumvoll M, Nurjhan N, Perriello et al. Metabolic effects of metformin in non-insulin-dependent diabetes mellitus. N Engl J Med. 1995; 333: 550-554.

26. Bailey CJ, Mynett KJ, Page T. Importance of the intestine as a site of metformin-stimulated glucose utilization. Br J Pharmacol. 1994; 112: 671-675.

27. Zhou G, Myers R LiY et al. Role of AMP- activated protein kinase in mechanism of metformin action. J Clin Invest. 2001; 108: 1167-1174.

28. Swaminathan K, Howlett HCS, Campbell IW. Metformin in diabetic pregnancy. J R Coll Physicians Edinb. 2009; 39: 10-14.

29. Feig DS, Briggs GG, Koren G. Oral antidiabetic agents in pregnancy and lactation: a paradigm shift? Ann Pharmacother. 2007; 41: 1174-1180.

30. Charles B, Norris R, Xiao X et al. Population pharmacokinetics of metformin in late pregnancy. Ther Drug Monit. 2006; $28:$ 67-72.

31. Hong YC, O’Boyle CP, Chen IC, et al. Metformin-associated lactic acidosis in a pregnant patient. Gynecol Obstet Invest. 2008; 66: 138-141.

32. Coetzee EJ, Jackson WP. Diabetes newly diagnosed during pregnancy: a 4-year study at Groote Schuur Hospital. S Afr Med J. 1979; 56: 467-475. 


\section{REFERENCES}

33. Coetzee EJ, Jackson WP. Pregnancy in established non-insulin-dependent diabetics. A five-and-a-half year study at Groote Schuur Hospital. S Afr Med J. 1980; 58: 795-802.

34. Coetzee EJ, Jackson WP. The management of non-insulin-dependent diabetes during pregnancy. Diabetes Res Clin Pract. 1985; 1: 281-287.

35. Hellmuth E, Damm P, Molsted-Pedersen L. Oral hypoglycemic agents in118 diabetic pregnancies. Diabet Med. 2000; 17: 507-511.

36. Yuan L, Ziegler R \& Hamann A. Metformin modulates insulin post-receptor signaling transduction in chronically insulin-treated Hep G2 cells. Acta Pharmacologica Sinica. 2003; 24: 55-60.

37. Ashokkumar N \& Pari L. Effect of N-benzoyl-D-phenylalanine and metformin on carbohydrate metabolic enzymes in neonatal streptozotocin diabetic rats. Clinica Chimica Acta. 2005; 351: 105-113.

38. Gunton JE, Delhanty PJ, Takahashi S \& Baxter RC. Metformin rapidly increases insulin receptor activation in human liver and signals preferentially through insulin-receptor substrate-2. J Clin Endocrinol and Metab. 2003; 88: 1323-1332.

39. Cheng JT, Huang CC, Liu IM, Tzeng TF \& Chang CJ. Novel mechanism for plasma glucose-lowering action of metformin in streptozotocin-induced diabetic rats. Diabetes. 2006; 55: 819-825.

40. Mithieux G, Guignot L, Bordet JC \& Wiernsperger N. Intrahepatic mechanisms underlying the effect of metformin in decreasing basal glucose production in rats fed a high-fat diet. Diabetes. 2002; 51: 139-143.

41. Lutz T, Estermann A, Haag S \& Scharrer E, Depolarization of the liver cell membrane by metformin. Biochimica et Biophysica ActaBiomembranes. 2001; 1513: 176-184.

42. Guigas B, Detaille D, Chauvin C, Batandier C, De Oliveira F, Fontaine E \& Leverve X. Metformin inhibits mitochondrial permeability transition and cell death: a pharmacological in vitro study. Biochemical journal. 2004; 382: 877-884.

43. Fulgencio JP, Kohl C, Girard J \& Pegorier JP. Effect of metformin on fatty acid and glucose metabolism in freshly isolated hepatocytes and on specific gene expression in cultured hepatocytes. Biochemical Pharmacology. 2001; 62: 439-446.

44. Kumar N \& Dey CS. Metformin enhances insulin signaling in insulin-dependent and independent pathways in insulin resistant muscle cells. Br J Pharmacol. 2002; 137: 329-336.

45. Diamanti-Kandarakis E, Christakou CD, Kandaraki E \& Economou FN. Metformin: an old medication of new fashion: evolving new molecular mechanisms and clinical implications in polycystic ovary syndrome. Europ J Endicrinol. 2010; 162: 193-212.

46. Iozzo P, Hallsten K, Oikonen V, Virtanen KA, Parkkola R, Kemppainen J, Solin O, Lonnqvist F, Ferrannini E, Knuuti J \& Nuutila P. Effects of metformin and rosiglitazone monotherapy on insulin-mediated hepatic glucose uptake and their relation to visceral fat in type 2 diabetes. Diabetes Care. 2003; 26: 2069-2074.

47. Virtanen KA, Lonnroth P, Parkkola R, Peltoniemi P, Asola M, Viljanen T, Tolvanen T, Knuuti J, Ronnemaa T, Huuponen R \& Nuutila P. Glucose uptake and perfusion in subcutaneous and visceral adipose tissue during insulin stimulation in non-obese and obese humans. J Clin Endocrinol and Metab. 2002; 87: 3902-3910.

48. Nestler JE \& Jakubowicz DJ. Decreases in ovarian cytochrome P450c 17 alpha activity and serum free testosterone after reduction of insulin secretion in polycystic ovary syndrome. N Engl J Med. 1996; 335: 617-623.

49. Muniyappa R, Montagnani M, Kon Koh K \& Quon M. Cardiovascular actions of insulin. Endocrine Reviews. 2007; 28: 463-491.

50. Gilbert C, Valois M, Koren G. Pregnancy outcome after first-trimester exposure to metformin: a meta-analysis. Fertil Steril. 2006; 86(3): 658

51. Hellmuth E, Damm P, Molsted-Pedersen L. Oral hypoglycemic agents in 118 diabetic pregnancies. Diabet Med. 2000; 17(7): 507-511.

52. Rowan JA, Hague WM, Goa W, Battin MR, Moore MP, MiG Trial Investigators. Metformin versus insulin for the treatment of gestational diabetes. N Engl J Med. 2008; 358(19): 2003-2015.

53. Velazquez EM, Vendoza S, Hamer T, Sosa \& Glueck CJ. Metformin therapy in polycystic ovary syndrome reduces hyperinsulinemia, insulin resistance, hyperandrogenemia and systolic blood pressure, while facilitating normal menses and pregnancy. Metabolism. 1994; 43: 647-654.

54. Diamanti-Kandarakis E. Insulin sensitizers targeting metabolic and reproductive consequences in polycystic ovary syndrome. In Polycystic Ovary Syndrome Current Controversies, From the ovary to the pancreas, Contemporary Endocrinology. Eds Andrea Dunaif, R Jeffrey Chang. Stephen Franks \& Richard S Legro. Humana Press. 2008;13:197-215.

55. Practice Committee of the American Society for Reproductive Medicine. Use of insulin sensitizing agents in the treatment of polycystic ovary syndrome. Fertility and Sterility. 2004; 82: S181-S183.

56. Moore LE, Briery CM, Clokey D et al. Metformin and insulin in the management of gestational diabetes mellitus: preliminary results of a comparison. J Reprod Med. 2007; 52: 1011-1015.

57. Kovo M, Haroutiunian S, Feldman N, Hoffman A, Glezerman M. Determination of metformin transfer across the human placenta using a dually perfused ex vivo placental cotyledon model. Eur J Obstet Gynecol Reprod Biol. 2008; 136: 29-33.

58. Rowan JA, Rush EC, Obolonkin V, Battin M, Wouldes T, Hague WM. Metformin in Gestational diabetes: The offspring Follow-up (MiG TOFU): body composition at 2 years of age. Diabetes Care. 2011; 34: 2279-2284.

59. Bertini AM, Silva J, Taborda W et al. Perinatal outcomes and use of the oral hypoglycemic agents. J Perinat Med. 2005; 33(15): 519-523. 


\section{REFERENCES}

60. Anjalakshi C, Balaji V, Balaji MS et al. A prospective study comparing insulin and glibenclamide in gestational diabetes mellitus in Asian Indian women. Diabetes Res Clin Pract. 2007; 76: 474-475.

61. Rowan JA, Hague W, Gao W, et al. For the MIG Trial Investigators. Metformin versus insulin for the treatment of gestational diabetes. N Engl J Med. 2008; 359: 106.

62. Moore LE, Clokey D, Rappaport VJ et al. Metformin compared with glyburide in gestational diabetes. Obstet Gynecol. 2010; 115: 55-59.

63. Silva JC, Pacheco C, Bizato J et al. Metformin compared with glyburide for the management of gestational diabetes. International Journal of Gynecology and Obstetrics 2010 [ Epub ahead of print].

64. Langer O, Conway D, Berkus MD et al. A comparison of glyburide and insulin in women with gestational diabetes mellitus. N Engl J Med. 2000; 343: 1134-1138.

65. Ogunyemi D, Jesse M \& Davidson M. Comparison of glyburide versus insulin in management of gestational diabetes mellitus. Endoc Pract. 2007; 13: 427-428.

66. National institute for Health and clinical Excellence London (2008) Diabetes in pregnancy: management of diabetes and its complications from preconception to the postnatal period [www.nice.org.uk/CG063].

67. The American College of Obstetricians and Gynecologists (2013) Gestational diabetes mellitus: Clinical management guidelines for obstetricians gynecologists. Obstet Gynecol. 2013; 122: 406-416.

68. Munshi S, Khandaker S. Evaluation of metformin vs insulin in the management of gestational diabetes mellitus: a prospective comparative study. Int J Reprod Contracept Obstet Gynecol. 2014; 3(2): 357-361.

69. Hague WM. Metformin in pregnancy and lactation. Aust Prescr. 2007; 30: 68-69.

70. Briggs GG, Ambrose PJ, Nageotte MP, Padilla G, Wan S. Excretion of metformin into breast milk and the effect on nursing infants. Obstet Gynecol. 2005; 105: 1437-1441.

71. Plagemann A, Harder T, Franke k, kohloff R. Long-term impact of neonatal breast-feeding on body weight and glucose tolerance in children of diabetic mothers. Diabetes Care. 2002; 25: 16-22.

72. Hebert MF, Ma X, Naraharisetti SB et al. The pharmacologic basis for better clinical practice. Clin Pharmacol ther. 2009; 85: 607-614.

73. Poolsup N, Suksomboon N, Amin M. Efficacy and safety of Oral Antidiabetic Drugs in comparison to insulin in treating gestational diabetes mellitus: A meta-analysis. Plos One. 2014; 10(9): e109985.

74. Garcia- Bournissen F, Feig DS \& Koren G. Maternal- fetal transport of hypoglycemic drugs. Clin pharmacokinet. 2003; 42(4): 303-313

75. Glueck CJ, Goldenberg N, Pranikoff J, Loftspring M, Sieve L, Wang P. Height, weight and motor-social development during the first 18 months of life in 126 infants born to 109 mothers with polycystic ovary syndrome who conceived on and continued metformin through pregnancy. Hum Reprod. 2004; 19(6): 1323-1330.

76. Glueck CJ, Wang P, Kobayashi S, Phillips H, Sieve-Smith L. Metformin therapy throughput pregnancy reduces the development of gestational diabetes in women with polycystic ovary syndrome. Fertil Steril. 2002; 77: 520-525.

77. Hawthorne G. Metformin use and diabetic pregnancy- has its time come? Diabetic Med. 2006; 23: 223-227.

78. Hague WM, Davoren PM, Mc Intyre D, Norris R, Xiaonian X, Charles B. Metformin crosses the placenta: a modulator for fetal insulin resistance? BMJ. 2003.

79. Bolen S, Feldman L, Vassy J, Wilson L, Yeh HC, Marinopoulos S et al. Systematic review: Comparative effectiveness and safety of oral medications for type 2 diabetes mellitus. Ann Inter Med. 2007; 147: 386-399.

80. Cryer DR, Nicholas SP, Henry DH, Mills DJ \& Stadel BV. Comparative outcomes study of metformin intervention versus conventional approach the COSMIC Approach Study. Diabetes Care. 2005; 28: 539-543.

81. Botta RM. Congenital malformations in infants of 517 pregestational diabetic mothers. Ann $1^{\text {st }}$ Super Sanita. 1997; 33(3): 307-311. 